\title{
Advances in the optimisation of apparel heating products: A numerical approach to study heat transport through a blanket with an embedded smart heating system
}

\author{
S.F. Neves ${ }^{\text {a, b }}$, S. Couto ${ }^{\text {c }}$, J.B.L.M. Campos ${ }^{\text {b }}$, T.S. Mayor ${ }^{\text {b, d, * }}$ \\ a Nanolayer Coating Technologies, LDA, Rua Fernando Mesquita, 2785, 4760-034 Vila Nova de Famalicão, Portugal \\ ${ }^{\mathrm{b}}$ Centro de Estudos de Fenómenos de Transporte, CEFT, Departamento de Engenharia Química, Faculdade de Engenharia da Universidade do Porto, Rua \\ Roberto Frias, 4200-465 Porto, Portugal \\ c Centre for Nanotechology and Smart Materials, CeNTI, Vila Nova de Famalicão, Portugal \\ d Swiss Federal Laboratories for Materials Science and Technology, EMPA, Lerchenfeldstrasse 5, 9014 St. Gallen, Switzerland
}

\section{H I G H L I G H T S}

- A numerical approach to optimise the performance of heating products is described.

- The approach was used to investigate the heat transport across a heating blanket.

- Several parameters and properties of textiles and of heating system were studied.

- Optimal compromise between the thermal performance of the product and the temperature oscillation along its surface.

\section{A R T I C L E I N F O}

\section{Article history:}

Received 27 March 2015

Accepted 8 May 2015

Available online 23 May 2015

\section{Keywords:}

Design optimisation

Apparel optimisation

Embedded heating elements

Heating blanket

Heat transfer simulation

Smart heating system

Numerical simulation

FEM approach

\begin{abstract}
A B S T R A C T
The optimisation of the performance of products with smart/active functionalities (e. g. in protective clothing, home textiles products, automotive seats, etc.) is still a challenge for manufacturers and developers. The aim of this study was to optimise the thermal performance of a heating product by a numerical approach, by analysing several opposing requirements and defining solutions for the identified limitations, before the construction of the first prototype. A transfer model was developed to investigate the transport of heat from the skin to the environment, across a heating blanket with an embedded smart heating system. Several parameters of the textile material and of the heating system were studied, in order to optimise the thermal performance of the heating blanket. Focus was put on the effects of thickness and thermal conductivity of each layer, and on parameters associated with the heating elements, e.g. position of the heating wires relative to the skin, distance between heating wires, applied heating power, and temperature range for operation of the heating system. Furthermore, several configurations of the blanket (and corresponding heating powers) were analysed in order to minimise the heat loss from the body to the environment, and the temperature distribution along the skin. The results show that, to ensure an optimal compromise between the thermal performance of the product and the temperature oscillation along its surface, the distance between the wires should be small (and not bigger than $50 \mathrm{~mm}$ ), and each layer of the heating blanket should have a specific thermal resistance, based on the expected external conditions during use and the requirements of the heating system (i.e. requirements regarding energy consumption/efficiency and capacity to effectively regulate body exchanges with surrounding environment). The heating system should operate in an ON/OFF mode based on the body heating needs and within a temperature range specified based on the blanket total thermal resistance, external temperature during use, and observed temperature on the blanket outer surface (safety and energy efficiency aspects).

The approach described in this work enabled the definition of the textile properties, the features of the embedded heating system, and the overall design of the system thus reducing substantially the number of prototypes needed for the final performance optimisation and fine-tuning.
\end{abstract}

๑) 2015 Elsevier Ltd. All rights reserved.

\footnotetext{
* Corresponding author. Swiss Federal Laboratories for Materials Science and Technology, EMPA, Lerchenfeldstrasse 5, 9014 St. Gallen, Switzerland.

E-mail addresses: tiago.sottomayor@empa.ch, tiagosmayor@gmail.com (T.S. Mayor).
} 


\section{Introduction}

One of the most important roles of clothing is to regulate the heat exchange between the human body and the environment, allowing the former to reach thermal equilibrium and thus thermal comfort. However, in many activities, the traditional passive insulation of the clothing can increase the risk of thermal discomfort, for example, by hampering the sweat evaporation during firefighter exercise or by restricting the wearer's physical activities in cold environments. This stimulates the demand for solutions with active temperature control between the body and the environment [1-4]. There are several ways to control the temperature of the microclimate between the skin and the clothing, such as: refrigeration fluids inside pipes embedded in the clothing [5], materials that accumulate/release energy (e. g. PCMs - Phase Change Materials; [6-10]), or heating wires integrated in the garment [11-13]. During the performance optimisation of these systems, often opposing requirements exist, e. g. batteries with high capacity but with low weight, systems with low heat losses but high breathability, etc. These opposing requirements demand the production of several prototypes and increase the duration and number of the development cycles of the final products. To shorten these cycles and fine-tune the thermal characteristics of the systems, the manufacturers and developers of clothing are searching for approaches that enable and accelerate the optimisation of various product families with smart/active functionalities (e. g. protective clothing, home textiles products, automotive seats, etc.).

The numerical simulation of the systems' thermal behaviour is one of the most promising approaches. Through modelling of the heat transport across a particular product, several design parameters and different heating methods can be studied in order to optimise the product performance. Kocbach et al. [14] used a finite element approach to evaluate the effect of several properties of a thermal stimulation equipment on the electrical stimulation of muscles. Couto et al. [13] used an identical approach to enhance the thermal performance of an electrical-heated mitt. Other models have been developed concerning how a particular combination of textile properties affects the body heat loss $[15,16]$, the water distribution inside clothing [17], the wind chill effect [18-21], and how the geometric features of the microclimates inside clothing affect the transport rates from the body [22-25].

To develop electrically heated products several aspects need to be considered (e.g. heating power, and system operating temperature; [26]). The usual procedure is to construct a substantial number of prototypes, and to assess their thermal performance by manikin tests [11,27-29] or human wear trials [11,30]. However, before the manufacture of the first prototype, a numerical approach can be used, allowing the identification of performance bottlenecks and possible solutions to maximise performance. For example, in the development of heating systems based on heating wires [11,12], the thermal performance can be improved by adjusting the operating power $[12,28]$ and considering modifications in the size and life of the batteries. Alternatively, one can increase the thermal resistance of the encapsulating layers, minimising heat losses from the body to the environment. However, this solution may also have drawbacks if the thermal resistance is increased through the change of the material thickness, because of the added weight and decreased breathability [31-33]. Instead, the impact of each heating element can be optimised by locating the wires in specific body regions. Hickey et al. [11] reported that heating wires systems embedded in military boots and gloves enhances the thermal protection when exposed to temperatures of $-40{ }^{\circ} \mathrm{C}$. These heating systems impose a constant heat flux $[11,12,28]$, which restricts the range of environmental conditions in which the user feels comfortable [12]. This discomfort is especially felt when environmental conditions are substantially different from those for which the operating power of the heating system was specified. To overcome this constraint, the heating system can be adjustable and controlled based on the ambient or heating wire temperature, as reported by Couto et al. [13].

To shorten development cycles and the number of prototypes manufactured, we developed a numerical approach to study and improve the performance of a bedding smart system with embedded heating elements. In this analysis, the effects of the wires distribution and of the properties of textile layers (i.e. thermal conductivity and thickness) on the product thermal performance were studied. Several configurations of the blanket were analysed in order to minimise the heat removed from the body to the environment, to ensure a homogeneous temperature distribution on the skin, and a minimum operating power required by the heating system. This numerical approach provides valuable information about the overall design of apparel heating products.

\section{Formulation of the problem}

The perception of thermal comfort during sleep can be influenced by changes in the conditions of the surrounding environment (e. g. changes on temperature, relative humidity, and air velocity inside the room). One way to mitigate the impact of these changes is to use a blanket with an embedded heating system (Fig. 1), equipped with adjustable operating power as a function of the heating needs. During sleep, the blanket must ensure the wearer's skin temperature is within a comfort range $\left(31-37^{\circ} \mathrm{C}\right.$, [34-36]), even if the thermal conditions change in the room (e. g. increase of ventilation from a window). In this scenario, the heating system must counterbalance the amount of energy removed from the blanket, so that the user does not feel the environment changes. This modification in energy supply has several implications both in the construction of the heating system (e. g. size batteries and associated electronics) and in terms of safety (e. g. burn hazard).

To minimise heat losses to the environment, the heating elements should be placed near the skin (Fig. 1). However, such arrangement increases the local temperature of the skin, which may lead to substantially lower temperatures in regions of the skin far from the heating elements. To mitigate this effect, the distance between wires must be small to the extent that it does not affect the stiffness of the final structure (since it is expected for the heating wires not to be detectable by touch). A compromise between the thermal performance of the product and the applicability of the solution should thus be found. To optimise the thermal performance of the blanket, the effects of several parameters and properties of the textile material were studied, such as those influencing the thermal resistance of each layer (i.e. thickness and thermal conductivity), and also of parameters associated with the heating wires operation (e. g. distance between wires, heating power, and operating temperature).

A transfer model was developed in Section 2.1 to evaluate the transfer of thermal energy from the skin to the environment, across a heating blanket with properties as given in Section 2.2.

\subsection{Transfer model and boundary conditions}

The two-dimensional simulation domain (blue dotted line in Fig. 2) encloses a region of the blanket with one heating wire. The boundaries 1 and 2 are the skin and the blanket outer surface, respectively. The energy is transferred by convection (natural convection) and thermal radiation from boundary 1 to the ambient.

We can express the conservative energy equation for the blanket control volume by, 




$\rho_{\text {textile }} \cdot C_{p_{\text {textile }}} \cdot \frac{\partial T}{\partial t}+\nabla\left(-k_{\text {textile }} \cdot \nabla T\right)=0$

where the first and the second terms represent the energy accumulation rate and the heat transfer rate by conduction, respectively. In equation (2.1), $\rho_{\text {textile, }} C p_{\text {textile, }}$ and $k_{\text {textile }}$ are respectively, the density, the specific heat, and the thermal conductivity of the textile layers. The textile material was assumed homogeneous and with properties as given in Table 1 (details on textile characterisation are given in Section 2.2). The heating elements were considered to be made of stainless steel (Table 1) with circular shape (Fig. 2).

The 2D model considers a boundary (line 1, Fig. 2) exposed to ambient air at a low temperature $\left(10^{\circ} \mathrm{C}\right)$, where heat is removed by natural convection and radiant exchange while the other boundary (line 2, Fig. 2) contacts the skin where the body releases a constant basal heat flux ( $\mathrm{q}_{\text {basal }}=45 \mathrm{~W} \mathrm{~m}^{-2}$; [35-39]). Numerically, the former is a Neumann boundary condition (i. e. heat transferred to the ambient by convection and radiation, equation (2.2)) while the latter is a Dirichlet boundary condition (i. e. constant heat flux, equation (2.3)).

$-\left.k_{\text {textile }} \cdot \nabla T\right|_{x=L}=h_{\mathrm{c}} \cdot\left(T-T_{\mathrm{amb}}\right)+\varepsilon_{\mathrm{r}} \cdot \sigma \cdot\left(T^{4}-T_{\mathrm{amb}}^{4}\right)$

$-\left.k_{\text {textile }} \cdot \nabla T\right|_{x=0}=\mathrm{q}_{\text {basal }}$

In equation (2.2), $h_{\mathrm{c}}$ is the convective heat transfer coefficient, $\varepsilon_{\mathrm{r}}$ the emissivity of the outer surface of the blanket, $\sigma$ the Stefan-Boltzmann constant, $T$ the temperature of the blanket, and $T_{\mathrm{amb}}$ the temperature of the environment. The convective heat transfer coefficient was calculated assuming that the blanket surface is flat, horizontal, and the heat exchange from the surface to the environment occurs by natural convection (line 1, Fig. 2).
Accordingly, the Nusselt number ( $\mathrm{Nu}$ ) can be expressed [40] by the expression,

$N u=\frac{h_{c} \cdot L_{c}}{k_{\text {air }}}=0.54 \cdot R a_{L}^{1 / 4}$

where $L_{c}$ is the characteristic length of the surface (i.e. $75 \mathrm{~mm}$; [40]), $k_{\text {air }}$ the thermal conductivity of air, and $\mathrm{Ra}_{\mathrm{L}}$ the Rayleigh number (equation (2.5)).

$\operatorname{Ra}_{L}=\frac{g \cdot \beta \cdot\left(T_{\text {surface }}-T_{\mathrm{amb}}\right) \cdot L_{c}^{3}}{v^{2}} \cdot \operatorname{Pr}$

The Rayleigh number is function of the temperature of the outer surface of the blanket ( $\left.T_{\text {surface }}\right)$, of the air properties at the average temperature of the fluid, and of the Prandtl number (Pr).

The wire was modelled as a source term, whose value depends on the type of operation of the heating system: continuous (constant heating power; Section 3.1 and 3.2) and adjustable (function of wire temperature; Section 3.2). The room temperature was taken constant $\left(10^{\circ} \mathrm{C}\right.$; Fig. 2$)$, and the blanket was assumed in equilibrium with the room prior to skin contact onset.

To solve the governing equation (equation (2.1)), a finite element approach was used [41]. The equation was discretized through a second order discretization scheme. The discretized equation was solved with a time-step of $1 \mathrm{~s}$, in a grid with $36 \times 10^{3}$ nodes (found adequate to ensure grid-independent results).

The following section explains the assumptions and experimental procedures used to determine the characteristics of the blanket layers and wires.

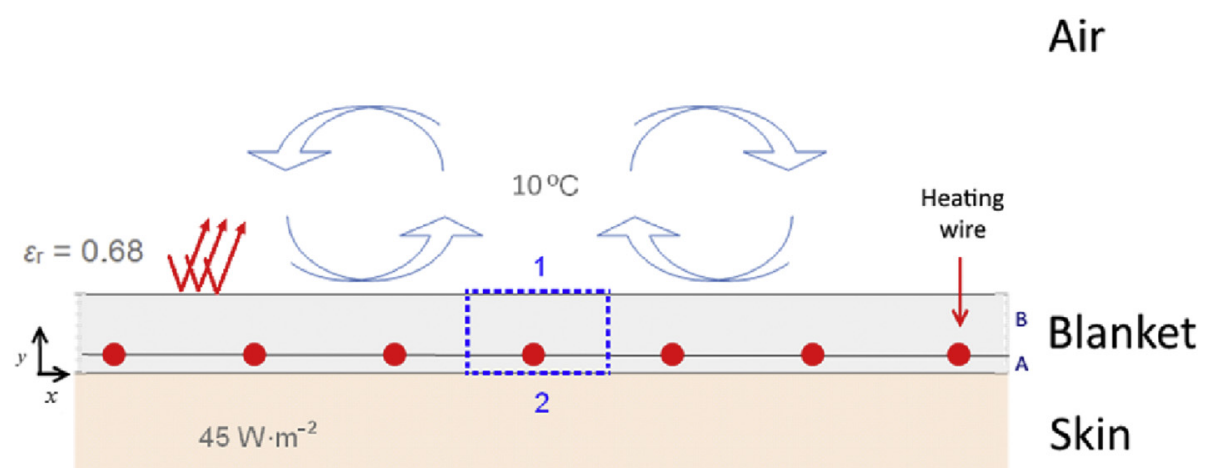

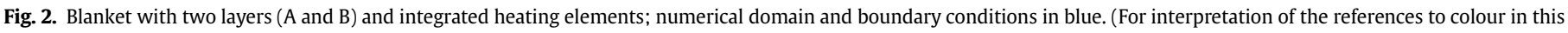
figure legend, the reader is referred to the web version of this article.) 
Table 1

Properties of the blanket (layer A and layer B), and of the heating wires (Fig. 2).

\begin{tabular}{|c|c|c|c|c|c|}
\hline Parameter & Unit & Layer A & Layer B & Heating wire & Source \\
\hline Thickness or diameter & $\mathrm{mm}$ & 0.17 & 5.64 & 1.00 & Experimental $[42,43]$ \\
\hline Thermal conductivity & $\mathrm{W} \mathrm{m}{ }^{-1} \mathrm{~K}^{-1}$ & $4.25 \times 10^{-2}$ & $3.94 \times 10^{-2}$ & $44.5^{\mathrm{a}}$ & Calculated \\
\hline Thermal resistance & $\mathrm{m}^{2} \mathrm{~K} \mathrm{~W}^{-1}$ & $4.0 \times 10^{-3}$ & $14.3 \times 10^{-2}$ & - & Experimental [44] \\
\hline Density & $\mathrm{kg} \mathrm{m}^{-3}$ & 358.2 & 103.6 & $7850.0^{\mathrm{a}}$ & Experimental $[43,45-49]$ \\
\hline Specific heat & $\mathrm{J} \mathrm{kg}^{-1} \mathrm{~K}^{-1}$ & 370.0 & 622.0 & $475.0^{\mathrm{a}}$ & Calculated [50] \\
\hline Emissivity & - & - & 0.68 & - & Estimated $[51,52]$ \\
\hline
\end{tabular}

a Manufacturer information.

\subsection{Properties and characteristics of the textile layers and heating elements}

The properties of the blanket layers and the characteristics of the heating wires are summarised in Table 1.

The thickness, density, thermal resistance, and thermal conductivity of the inner and outer layers of the blanket (layer A and B, Table 1) were determined by experimental procedures [43], while the specific heat was estimated under equilibrium conditions $\left(20{ }^{\circ} \mathrm{C}\right.$ and relative humidity of $65 \%$, [50]). The emissivity of the outer surface of the blanket was assumed 0.68 (i.e. typical values of textile emissivity are reported in literature between 0.68 and 0.90 ; [51-53]).

The textile thickness ( $L$; Table 1$)$ was measured with an apparatus featuring a pressure-foot exerting a specific pressure on the textile $[47,49,54]$. The measurements were conducted according to the standard ISO 9073-2: 1995 [42] and applying a constant pressure of $1.1 \mathrm{kPa}$ to the textile.

The textile density (Table 1) was calculated by weighing a known volume of sample [45-49], after stabilisation of its moisture content (by exposure to air environment at $20^{\circ} \mathrm{C}$ and $65 \%$ of relative humidity).

The thermal resistance of the textile ( $R_{\mathrm{ct}, \text { textile; Table } 1) \text { was }}$ obtained by an indirect measurement, based on the international standard ISO 11092:1993 (E) [44]. By definition, the thermal resistance of a flat textile is directly proportional to its thickness, and inversely proportional to its thermal conductivity ( $\left.k_{\text {textile}}\right)$,

$R_{\mathrm{ct}, \text { textile }}=\frac{L}{k_{\text {textile }}}$

The thermal conductivity of the textile was calculated by equation (2.6).

The properties of the heating wires (thermal conductivity, density, and specific heat; Table 1) were estimated based on manufacturer specification sheets.

\section{Optimisation of the apparel heating system}

The model described in Section 2.1 was used to simulate the heat transfer across a blanket with embedded heating elements. In Section 3.1, the effects of the wires distribution and of the properties of textile layers (i.e. thermal conductivity and thickness) were studied. In Section 3.2, several configurations of the blanket were analysed in order to minimise the heat removed from the body to the environment, to ensure a homogeneous temperature distribution on the skin, and a minimum operating power required by the heating system.

\subsection{Influence of the wires distribution and apparel thermal properties on skin temperature}

To study the influence of the distribution of heating wires inside the blanket on the temperature along the skin, four distances between the wires were tested in steady-state, for an overall operating power ensuring an average skin temperature of $34{ }^{\circ} \mathrm{C}$. The properties of each layer of the blanket and wires are shown in Table 1.

Fig. 3 shows how the distance between the heating elements affects the temperature distribution along the skin, being the highest temperature in the region adjacent to the heating wires. For large distances between wires (e. g. $50 \mathrm{~mm}$ ) the average skin temperature of $34{ }^{\circ} \mathrm{C}$ is achieved only when a maximum temperature of $70{ }^{\circ} \mathrm{C}$ is attained near the heating element (50 mm, Fig. 3), something unacceptable for safety reasons.

For distances of wires between $17 \mathrm{~mm}$ and $50 \mathrm{~mm}$, the maximum temperature in the skin is still greater than $40{ }^{\circ} \mathrm{C}$ (Fig. 3 ), which could still cause pain to the user [36]. To avoid this, the wires distance must be less than $12.5 \mathrm{~mm}$ apart. For the current conditions, a distance of $12.5 \mathrm{~mm}$ and an average operating power of $42.3 \mathrm{~W} \mathrm{~m}^{-2}$, ensures an average skin temperature of $34^{\circ} \mathrm{C}$. However, the distance in question may raise concerns in terms of construction of the blanket (due to limitations in production machines) and its mechanical structure (which can become very rigid and heavy). Therefore, other solutions allowing for a bigger distance between the wires were pursued, e.g. by changing the thermal resistance of the layer between the heating wires and the skin. The effect of the thermal resistance of the inner layer of the blanket (A Fig. 2) was analysed by changing its thickness and its thermal conductivity. For each pair of layer thickness - distance between wires, the operating power of the wires and the thermal conductivity of the inner layer, that ensures a maximum oscillation of $10^{\circ} \mathrm{C}$ in the skin temperature (Fig. 4), were calculated.

As shown in Fig. 4, an inner layer of $1 \mathrm{~mm}$ and a distance between wires of $12.5 \mathrm{~mm}$ implies that the thermal conductivity of the layer must be $0.03 \mathrm{~W} \mathrm{~m}^{-1} \mathrm{~K}^{-1}$, for the skin temperature to oscillate by $10{ }^{\circ} \mathrm{C}$ along its surface. However, when the distance between wires increases to $50 \mathrm{~mm}$, the required thermal

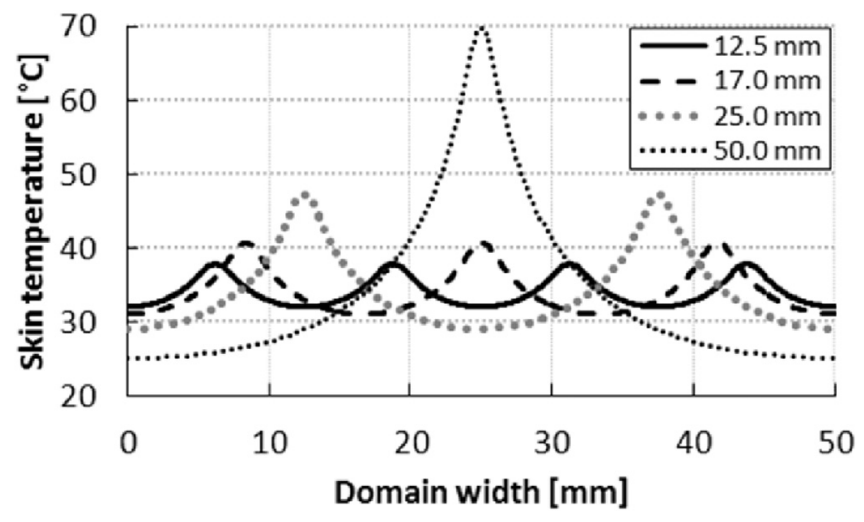

Fig. 3. Skin temperature distribution (along $x ; y=0 \mathrm{~mm}$; Fig. 2) for several distances between wires $(12.5,17.0,25.0$, and $50.0 \mathrm{~mm})$ in steady-state, with a heat flux ensuring an average skin temperature of $34^{\circ} \mathrm{C}$. 


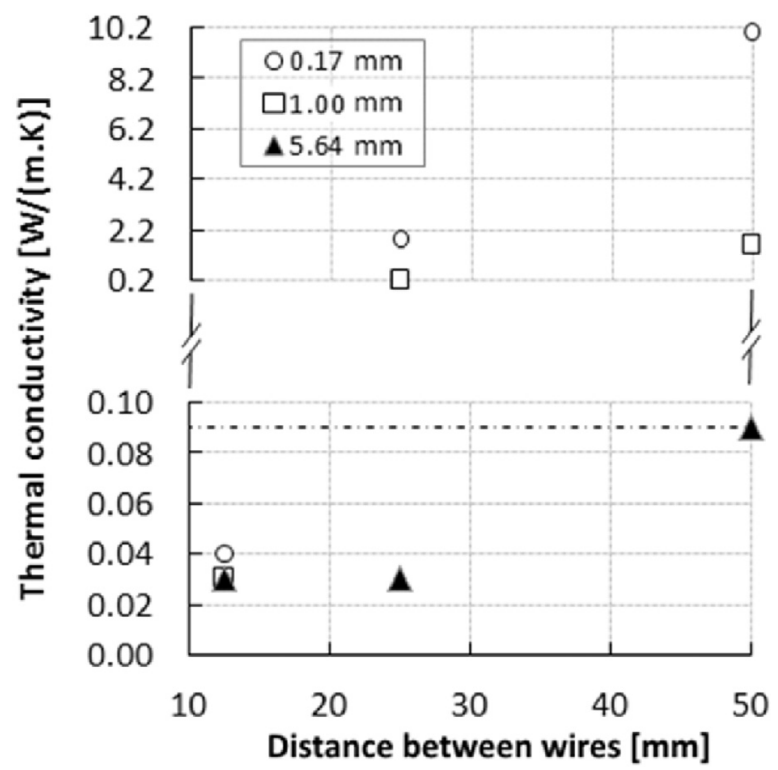

Fig. 4. Minimum thermal conductivity of the inner layer (A, Fig. 2) for several distances between wires $\left(12.5,25.0\right.$, and $50 \mathrm{~mm}$ ) that ensures an oscillation of $10^{\circ} \mathrm{C}$ along the skin surface, for various inner layer thicknesses $(0.17,1.00$, and $5.64 \mathrm{~mm})$, and constant thickness of the outer layer (5.64 mm, Table 1).

conductivity increases to $1.6 \mathrm{~W} \mathrm{~m} \mathrm{~m}^{-1} \mathrm{~K}^{-1}$. Given that the textiles have a relatively low thermal conductivity (between 0.03 and $0.09 \mathrm{~W} \mathrm{~m}^{-1} \mathrm{~K}^{-1}$, [55]), Fig. 4 shows that, to achieve a maximum oscillation of $10^{\circ} \mathrm{C}$ along the skin, the distance between wires must be smaller than $50 \mathrm{~mm}$ or the thermal resistance of the inner layer must be substantially higher than $4.0 \times 10^{-3} \mathrm{~m}^{2} \mathrm{~K} \mathrm{~W}^{-1}$ (Table 1 ). However, if the thermal resistance of the inner layer is increased without increasing also the thermal resistance of the external layer, a bigger proportion of the heat released by the wires would be lost to the environment. This would diminish the system efficiency, so, to avoid it, the properties of the outer layer (B, Fig. 2) should also be optimised. In the following section, different configurations for both layers of the blanket were analysed in order to optimise the performance of the heating system.

\subsection{Influence of different apparel configurations}

The results shown in Section 3.1 indicate that the distance between wires must be small enough to ensure a narrow temperature oscillation along the skin surface. However, due to construction and ergonomics concerns, preference was given to a distance between wires of $50 \mathrm{~mm}$. To reduce the temperature oscillation, the thermal resistance of the inner layer was increased (despite the associated decrease in the heating system performance) and further attention was put on the properties of the blanket outer layer. In this section, the effect of the thermal resistance of both layers in skin temperature was studied, for four blanket configurations as shown in Table 2. In configurations II, III, and IV (Table 2), both layers are made of the same material (thus having the same thermal conductivity), while in configuration I the fibres of the inner layer are different from those of the outer layer (Table 1).

The increasing distance of the heating elements relative to the skin implies that, from configuration I to II (Table 2), the energy lost to the environment increases, and consequently, more energy must be supplied by the heating system (in this case, an increase of $19 \mathrm{~W} \mathrm{~m}^{-2}$, Fig. 5). However, there is a decrease in the maximum skin temperature (around $12.8{ }^{\circ} \mathrm{C}$ ) while the minimum temperature remains constant, since the total thermal resistance of the blanket is approximately the same for both configurations (Table 2).

To reduce the heat losses to the environment, the thermal resistance of the outer layer was roughly doubled (from configuration II to III, Table 2). The heat flux needed to maintain the average skin temperature around $34{ }^{\circ} \mathrm{C}$ decreased by $34 \mathrm{~W} \mathrm{~m}^{-2}$ (from configuration II to III; Fig. 5) and the maximum temperature on the skin also decreased from 56.8 to $44.9^{\circ} \mathrm{C}$, the latter being, yet, still very high [36]. To diminish further the maximum temperature in the skin, the thermal resistance of the outer layer was further

Table 2

Thermal resistance of each blanket layer for a distance between wires of $50 \mathrm{~mm}$ (Fig. 2)

\begin{tabular}{|c|c|c|c|c|}
\hline \multirow[t]{2}{*}{ Configuration } & \multicolumn{2}{|l|}{ Layer A } & \multicolumn{2}{|l|}{ Layer B } \\
\hline & Thickness [mm] & Thermal resistance $\left[\mathrm{m}^{2} \mathrm{~K} \mathrm{~W}^{-1}\right]$ & Thickness [mm] & Thermal resistance $\left[\mathrm{m}^{2} \mathrm{~K} \mathrm{~W}^{-1}\right]$ \\
\hline I & 0.17 & $4.0 \times 10^{-3}$ & 5.64 & $14.3 \times 10^{-2}$ \\
\hline II & 2.82 & $7.2 \times 10^{-2}$ & 2.82 & $7.2 \times 10^{-2}$ \\
\hline III & 2.82 & $7.2 \times 10^{-2}$ & 5.92 & $15.0 \times 10^{-2}$ \\
\hline IV & 2.82 & $7.2 \times 10^{-2}$ & 7.89 & $20 \times 10^{-2}$ \\
\hline
\end{tabular}




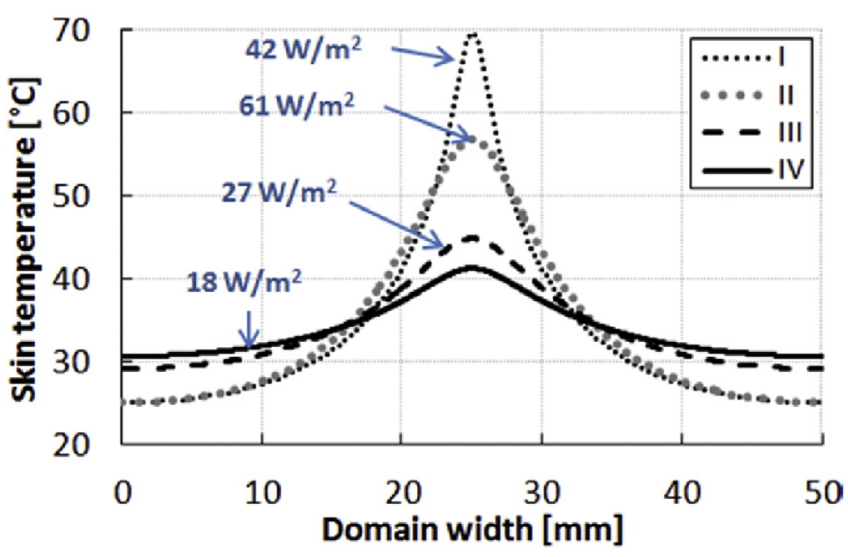

Fig. 5. Skin temperature distribution (along $x ; y=0 \mathrm{~mm}$ ) for four blanket configurations (Table 2) in steady-state, with heat fluxes that ensure an overall skin temperature of $34{ }^{\circ} \mathrm{C}$ (distance between the wires $=50 \mathrm{~mm}$ ).

increased by $25 \%$ (from configuration III to IV, Table 2), but the resulting decrease in temperature was only of $3.6^{\circ} \mathrm{C}$ (Fig. 5), and the maximum skin temperature was still above $40{ }^{\circ} \mathrm{C}$ (threshold for pain, [36]).

No further increases of the thermal resistance of the outer layer were considered since, for configuration IV, the heating power is already very low ( $18 \mathrm{~W} \mathrm{~m} \mathrm{~m}^{-2}$, Fig. 5), thus, indicating that a more insulating layer would render the heating system unfit for control the body heat loss. Alternatively, we studied an ON/OFF operation mode of the heating system. The system is ON (i.e. providing heat) until a given maximum temperature of the wires $\left(T_{\max }\right)$ is reached, after which the system is OFF (until a given minimum temperature is reached again, $T_{\min }$ ). The specification of the operating temperature range prevents the skin temperature from exceeding $40^{\circ} \mathrm{C}$ (to avoid risk of burns).

In Fig. 6, the wire and skin temperatures are shown for the configurations III and IV (Table 2) with the heating system operating in the mentioned ON/OFF mode (based on the temperature of the wire). The system was adjusted to ensure a maximum temperature in the skin of $37^{\circ} \mathrm{C}$ (Fig. $6 \mathrm{~b}$ and d), providing heating when the wire temperature drops to $32^{\circ} \mathrm{C}$ (Fig. $6 \mathrm{a}$ and c) and as long as its temperature is below the maximum defined value (which depends on the thermal properties of the blanket layers). For example, for the blanket configuration with lower thermal resistance (configuration III, Table 2), a skin temperature of $37{ }^{\circ} \mathrm{C}$ (skin zone 1, Fig. 6b) is reached when the wire temperature is $39.8^{\circ} \mathrm{C}$ and $40.7^{\circ} \mathrm{C}$, for constant heat flux of 50 and $100 \mathrm{~W} \mathrm{~m}^{-2}$, respectively (Fig. 6a). When considering the configuration with the higher thermal resistance (configuration IV, Table 2), the mentioned $37{ }^{\circ} \mathrm{C}$ on the skin is reached (skin zone 1, Fig. 6d) at lower wires temperatures, i.e. $38.5{ }^{\circ} \mathrm{C}$ and $39.3{ }^{\circ} \mathrm{C}$, respectively (Fig. $6 \mathrm{c}$ ). The minimum temperature in regions of the skin farthest from the heating wires is in all the cases lower than $32{ }^{\circ} \mathrm{C}$ (skin zone 2, Fig. $6 \mathrm{~b}$ and d).

In all scenarios evaluated in Fig. 6, the skin temperature near the heating elements is within the values reported as comfortable (31 and $\left.37^{\circ} \mathrm{C} ;[34-36]\right)$. The results shown in Fig. 6 indicate that, for a $50 \mathrm{~mm}$ distance between wires, the configuration IV of the blanket (Table 2) is the most interesting of the two analysed, giving the lowest oscillation of temperature along the skin (between 30.4 and $37^{\circ} \mathrm{C}$, i.e. skin zones 1 and 2 of Fig. 6, respectively).

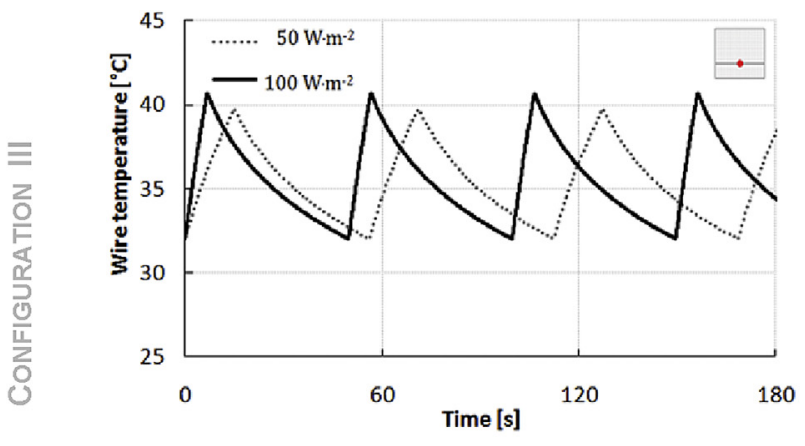

(a)

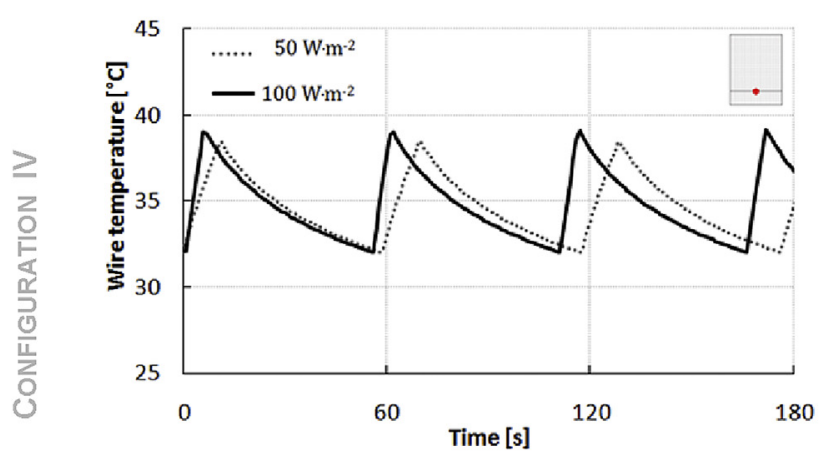

(c)

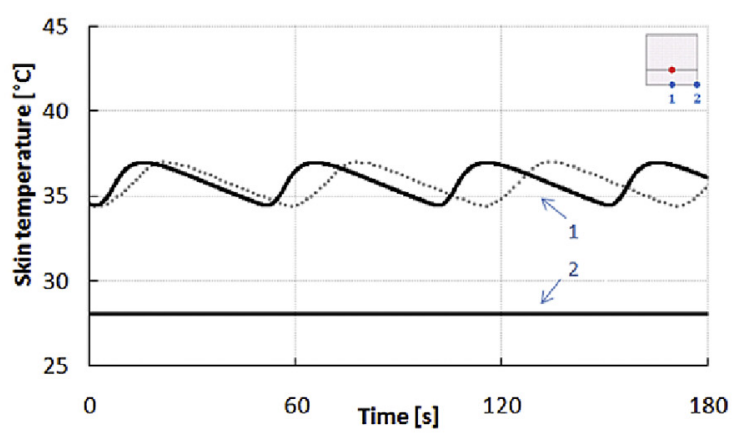

(b)

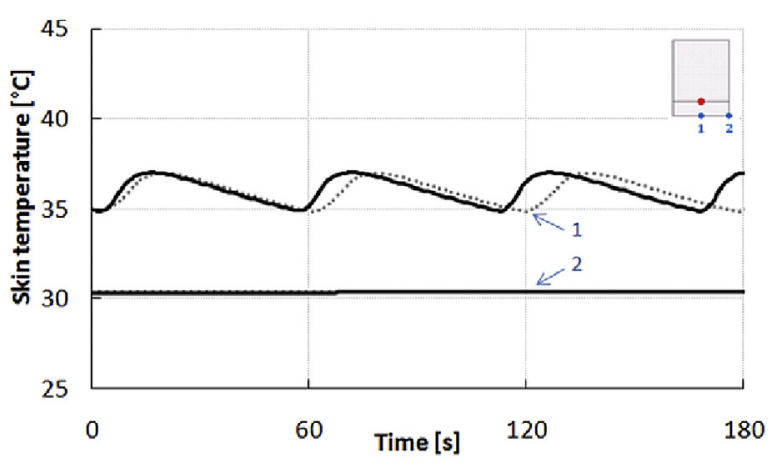

(d)

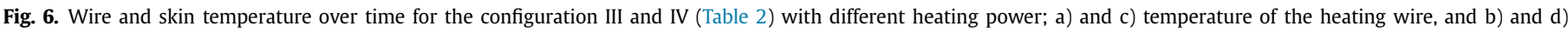
temperature of two different zones of the skin (dot 1 and 2); distance between the wires $=50 \mathrm{~mm}$. 
The approach described here allowed the identification of the textile properties (thickness and thermal conductivity), the features of the embedded heating system (heating power and operating temperature), and the overall design of the system (wires distribution), that optimise its performance as a way to control the body heat exchange with the surrounding environment. The described numerical approach allows to substantially reduce the number of prototypes needed for the final performance optimisation while enabling to accommodate increasingly shorten development cycles.

\section{Conclusions}

A numerical analysis was developed to study and optimise the thermal performance of a blanket with an embedded smart heating system. The numerical approach allowed the prediction of the skin temperature as a function of the blanket properties (thermal conductivity, thickness, external emissivity) and of the features of the heating elements (position relative to the skin, distance between wires, heating power, and operating temperature). The results show that to design a heating blanket with an embedded heating system one should:

(i) Put the heating elements as close as possible (but not further than $50 \mathrm{~mm}$ ), within relatively insulating layers to damp temperature oscillations along its surface;

(ii) Specify the thermal resistance of the layers based on the expected external conditions during use, and the requirements of the heating system (i.e. requirements regarding energy consumption/efficiency, and capacity to effectively regulate body exchanges with surrounding environment);

(iii) Design the system to operate in an ON/OFF fashion based on heating needs and prevailing external temperatures during use;

(iv) Specify temperature ranges for operation of the system based on the chosen blanket total thermal resistance and observed temperature in the blanket outer surfaces (safety and energy efficiency aspects).

The described approach enabled to address performance and developments aspects in the optimisation of an apparel product with an embedded heating system. The numerical approach allowed to substantially reduce the number of physical prototypes needed for the final performance fine-tuning, which is critically important in optimisation activities (e. g. of protective clothing or sports apparel).

\section{Acknowledgements}

The support provided by Fundação para a Ciência e a Tecnologia (FCT), Portugal under grant number SFRH/BDE/51382/2011 is gratefully acknowledged.

\section{References}

[1] K. Tesch, M.W. Collins, T.G. Karayiannis, M.A. Atherton, P. Edwards, Heat and mass transfer in air-fed pressurised suits, Appl. Therm. Eng. 29 (7) (2009) 1375-1382.

[2] Y. Yang, J. Stapleton, B.T. Diagne, G.P. Kenny, C.Q. Lan, Man-portable personal cooling garment based on vacuum desiccant cooling, Appl. Therm. Eng. 47 (2012) 18-24.

[3] T.C. Ernst, S. Garimella, Demonstration of a wearable cooling system for elevated ambient temperature duty personnel, Appl. Therm. Eng. 60 (1-2) (2013) 316-324.

[4] M. Bühler, a. M. Popa, L.J. Scherer, F.K.S. Lehmeier, R.M. Rossi, Heat protection by different phase change materials, Appl. Therm. Eng. 54 (2) (2013) 359-364.
[5] B.M.N.R. de Carvalho, F.A.D.S. Simões, R.P.P. Dias, EP 1679984 B1-Autonomous Garment with Active Thermal Control and Powered by Solar Cells, 2008 .

[6] N. Sarier, E. Onder, Organic phase change materials and their textile applications: an overview, Thermochim. Acta. 540 (2012) 7-60.

[7] B. Pause, Nonwoven protective garments with thermo-regulating properties, J. Ind. Text. 33 (2) (2003) 93-99.

[8] B. Ying, Y. Kwok, Y. Li, Q. Zhu, C. Yeung, Assessing the performance of textiles incorporating phase change materials, Polym. Test. 23 (5) (2004) 541-549.

[9] R.E. Reinertsen, F. Hilde, K. Holbo, R. Nesbakken, J. Reitan, A. Royset, M.S. Le Thi, Optimizing the performance of phase-change materials in personal protective clothing systems, Int. J. Occup. Saf. Ergon. (JOSE) 14 (1) (2008) 43-53.

[10] S. Mondal, Phase change materials for smart textiles - an overview, Appl. Therm. Eng. 28 (2008) 1536-1550.

[11] C.A.J. Hickey, A.A.J. Woodward, W.E. Hanlon, A Pilot Study to Determine the Thermal Protective Capability of Electrically Heated Clothing and Boot Inserts, Maryland, U.S.A, 1993.

[12] F. Wang, Evaluation of the Performances of Electrically Heated Clothing, 2010, pp. $10,12,13$

[13] S. Couto, J.B.L.M. Campos, T.S. Mayor, On the performance of a mitt heating multilayer: a numerical study, Int. J. Cloth. Sci. Technol. 23 (5) (2011) 373-387.

[14] J. Kocbach, L. Mohn, O. Brix, A simulation approach to optimizing performance of equipment for thermostimulation of muscle tissue using COMSOL multiphysics, Biophys. Bioeng. Lett. 4 (2) (2011) 9-33.

[15] S.F. Neves, J.B.L.M. Campos, T.S. Mayor, Numerical simulation study on the heat and mass transfer through multi-layer textile assemblies, in: COMSOL Conference 2012 Milan, 2012.

[16] X. Yin, Q. Chen, N. Pan, A more comprehensive transport model for multilayercloth for perspiration based infrared camouflage, Appl. Therm. Eng. 68 (1-2) (2014) 10-19.

[17] H. Wu, J. Fan, Study of heat and moisture transfer within multi-layer clothing assemblies consisting of different types of battings, Int. J. Therm. Sci. 47 (5) (2008) 641-647.

[18] P. Gibson, Modeling heat and mass transfer from fabric-covered cylinders, J. Eng. Fiber. Fabr. 4 (1) (2009) 1-8.

[19] S.F. Neves, J.B.L.M. Campos, T.S. Mayor, A numerical simulation study on the thermal performance of ventilated clothes, in: 6th European Conference on Protective Clothing, 2014.

[20] O. Neiva, F.T. Pinho, T.S. Mayor, A numerical study on the cooling power of an enhanced convection solution for footwear, in: Japan-Portugal Nanobiomedical Engineering Symposium, 2011, p. 2.

[21] R. Rocha, O. Neiva, J.B.L.M. Campos, F.T. Pinho, T.S. Mayor, A cooling solution for footwear - numerical analysis, in: The Fiber Society 2012 Spring Conference - Fiber Research for Tomorrow's Applications, 2012, pp. 230-231.

[22] T.S. Mayor, S. Couto, A. Psikuta, R. Rossi, A numerical analysis on the transport phenomena across horizontal clothing microclimates, in: 6th European Conference on Protective Clothing, 2014, p. 34.

[23] T.S. Mayor, S. Couto, A. Psikuta, R. Rossi, Advanced modelling of the transport phenomena across horizontal clothing microclimates with natural convection, Int. J. Biometeorol. (IJB) (2015), http://dx.doi.org/10.1007/s00484-015-0994-X.

[24] T.S. Mayor, S. Couto, A. Psikuta, R. Rossi, Transport phenomena in clothing wavy microclimates - a numerical study, in: Scientific Conference for Smart and Functional Textiles, Well-being, Thermal Comfort in Clothing, Design, Thermal Manikins and Modelling (Ambience14 \& 10i3m), 2014.

[25] T.S. Mayor, D. Oliveira, R. Rossi, S. Annaheim, Numerical simulation of the transport phenomena in tilted clothing microclimates, in: XVI International Conference on Environmental Ergonomics (ICEE'15), 2015.

[26] P. Xu, F. Wang, Electrically heated clothing (EHC) for protection against cold stress, in: F. Wang, C. Gao (Eds.), Protective Clothing: Managing Thermal Stress, Woodhead Publishing Limited, 2014, pp. 281-293.

[27] E.B. Elabbassi, S. Delanaud, K. Chardon, J.-P. Libert, V. Candas, Electrically heated blanket in neonatal care: assessment of the reduction of dry heat loss from a thermal manikin, Environ. Ergon. (2005) 431-435.

[28] F. Wang, H. Lee, Evaluation of an electrically heated vest (EHV) using a thermal manikin in cold environments, Ann. Occup. Hyg. 54 (1) (2010) $117-124$.

[29] M. Zhao, C. Gao, F. Wang, K. Kuklane, I. Holmér, J. Li, A study on local cooling of garments with ventilation fans and openings placed at different torso sites, Int. J. Ind. Ergon. 43 (3) (2013) 232-237.

[30] P. Webb, F.K. Klemm, Design of Ventilated Clothing, Wright-Patterson Air Force Base, Ohio, 1959

[31] T.S. Mayor, F. Wang, J. Léonard, M. Ribeiro, An interlaboratory study on measurements of clothing evaporative resistance with thermal manikins, in: The 5th European Conference on Protective Clothing and NOKOBETEF 10 (ECPC), 2012.

[32] F. Wang, G. Havenith, T.S. Mayor, K. Kuklane, J. Léonard, M. Zwolinska, S. Hodder, C. Wong, J. Kishino, X. Dai, Clothing real evaporative resistance determined by means of a sweating thermal manikin: a new round-robin study, in: Scientific Conference for Smart and Functional Textiles, Wellbeing, Thermal Comfort in Clothing, Design, Thermal Manikins and Modelling (Ambience14 \& 10i3m), 2014.

[33] F. Wang, S. del Ferraro, L.-Y. Lin, T. Sotto Mayor, V. Molinaro, M. Ribeiro, C. Gao, K. Kuklane, I. Holmér, Localised boundary air layer and clothing evaporative resistances for individual body segments 55 (7) (2012) 799-812.

[34] Ergonomics of the Thermal Environment - Estimation of Thermal Insulation and Water Vapour Resistance of a Clothing Ensemble, 2008, p. 78. ISO 9920. 
[35] N. Pan, P. Gibson, Thermal and Moisture Transport in Fibrous Materials, first ed., Wookhead Publishing Limited, 2006.

[36] K. Parsons, Human Thermal Environments, second ed., Taylor \& Francis, 2003.

[37] R.F. Goldman, B. Kampmann, Handbook on clothing, in: Biomedical Research, Second.,, 2007, pp. 1-3.

[38] B. Holand, Thermal manikin testing 3IMM, in: Proceedings of the 3rd International Meeting on Thermal Manikin Testing 3IMM, 1999, pp. 25-28.

[39] ISO 8996:2004(E), Ergonomics of the Thermal Environment - Determination of Metabolic Rate, vol. 44, 2004.

[40] Y.A. Çengel, Natural convection, in: Heat and Mass Transfer - a Pratical Approach, third ed., McGraw-Hill Science/Engineering/Math, 2007, pp. 468-469.

[41] O.C. Zienkiewicz, R.L. Taylor, P. Nithiarasu, The Finite Element Method for Fluid Dynamics, sixth ed, Elsevier Butterworth-Heinemann, 2005.

[42] ISO 9073-2, Textiles - Test Methods for Nonwovens - Part 2: Determination of Thickness, 1995

[43] S.F. Neves, J.B.L.M. Campos, T.S. Mayor, On the determination of parameters required for numerical studies of heat and mass transfer through textiles methodologies and experimental procedures, Int. J. Heat Mass Transf. 81 (2015) 272-282.

[44] ISO 11092:1993(E), Textiles - Physiological Effects - Measurement of Thermal and Water-vapour Resistance under Steady-state Conditions (Sweating Guarded-hotplate Test), 1993.

[45] J.R. Lawson, T.A. Pinder, Estimates of Thermal Conductivity for Materials Used in Fire Fighters' Protective Clothing, 2000. Gaithersburg, Maryland.

[46] C. Brasquet, P. Le Cloirec, Pressure drop through textile fabrics - experimental data modelling using classical models and neural networks, Chem. Eng. Sci. 55 (15) (2000) 2767-2778.

[47] G. Bedek, F. Salaün, Z. Martinkovska, E. Devaux, D. Dupont, Evaluation of thermal and moisture management properties on knitted fabrics and comparison with a physiological model in warm conditions, Appl. Ergon. 42 (6) (2011) 792-800.

[48] R.M. Laing, S.E. Gore, C.A. Wilson, D.J. Carr, B.E. Niven, Standard test methods adapted to better simulate fabrics in use, Text. Res. J. 80 (12) (2010) $1138-1150$.

[49] I. Salopek Čubrić, Z. Skenderi, A. Mihelić-Bogdanić, M. Andrassy, Experimental study of thermal resistance of knitted fabrics, Exp. Therm. Fluid Sci. 38 (2012) 223-228.

[50] P. Gibson, M. Charmchi, The use of volume-averaging techniques to predict temperature transients due to water vapor sorption in hygroscopic porous polymer materials, J. Appl. Polym. Sci. 64 (3) (1997) 493-505.
[51] D. Ding, T. Tang, G. Song, A. MacDonald, Characterizing the performance of a single-layer fabric system through a heat and mass transfer model - Part II: thermal and evaporative resistances, Text. Res. J. 81 (9) (2011) 945-958.

[52] D. Ding, T. Tang, G. Song, A. MacDonald, Characterizing the performance of a single-layer fabric system through a heat and mass transfer model - Part I heat and mass transfer model, Text. Res. J. 81 (4) (2010) 398-411.

[53] A. Ghazy, Air Gap in Protective Clothing during Flash Fire Exposure, University of Saskatchewan, 2011.

[54] S. Lee, S.K. Obendorf, Statistical modeling of water vapor transport through woven fabrics, Text. Res. J. 82 (3) (2012) 211-219.

[55] J.R. Lawson, W.D. Walton, N.P. Bryner, F.K. Amon, Estimates of Thermal Properties for Fire Fighters' Protective Clothing Materials, 2005.

\section{Nomenclature}

g: gravitational acceleration $\left[\mathrm{m} \mathrm{s}^{-2}\right]$

$h_{c}$ : convective heat transfer coefficient $\left[\mathrm{W} \mathrm{m} \mathrm{m}^{-2} \mathrm{~K}^{-1}\right]$

$k_{\text {air: }}$ : thermal conductivity of air $\left[\mathrm{W} \mathrm{m} \mathrm{m}^{-1} \mathrm{~K}^{-1}\right.$ ]

$k_{\text {textile: }}$ thermal conductivity of textile $\left[\mathrm{W} \mathrm{m}^{-1} \mathrm{~K}^{-1}\right.$ ]

$q_{\text {basal }}$ : basal metabolic rate $\left[\mathrm{W} \mathrm{m}^{-2}\right]$

$t$ : time [s]

$x, y$ : coordinates $[\mathrm{m}]$

$C p_{\text {textile: }}$ specific heat of textile $\left[\mathrm{J} \mathrm{kg}^{-1} \mathrm{~K}^{-1}\right]$

$L$ : thickness [m]

$L_{c}$ : characteristic length $[\mathrm{m}]$

Nu: Nusselt number [-]

Ra: Rayleigh number $[-]$

$R_{c t}$ : thermal resistance $\left[\mathrm{m}^{2} \mathrm{~K} \mathrm{~W}^{-1}\right]$

Pr: Prandtl number $[-]$

$T$ : temperature $[\mathrm{K}]$

Greek letters

$\varepsilon_{r}$ : emissivity [-]

$\rho_{\text {textile: }}$ density of textile $\left[\mathrm{kg} \mathrm{m}^{-3}\right]$

$\sigma$ : Stefan-Boltzmann constant $\left[\mathrm{m}^{2} \mathrm{~kg} \mathrm{~s}^{-2} \mathrm{~K}^{-1}\right]$

$v$ : kinematic viscosity of air $\left[\mathrm{m}^{2} \mathrm{~s}^{-1}\right]$

$\beta$ : coefficient of volume expansion $\left(\beta=1 / T_{\text {film }}\right)\left[\mathrm{K}^{-1}\right]$ 